\title{
TOWARDS A META-MODEL FOR COLLABORATIVE CONSTRUCTION PROJECT MANAGEMENT
}

\author{
Martin Keller, Karsten Menzel, Raimar J. Scherer \\ Institute of Construction Informatics, Technical University of Dresden, GERMANY \\ \{martin.keller; karsten.menzel; raimar.j.scherer\}@cib.bau.tu-dresden.de
}

\begin{abstract}
Projects in the building industry are extremely dynamic and affected by several constraints. Therefore, common principles should be established throughout the construction industry that allows flexibly specifying and combining construction project information for the inter-organisational collaboration. New members should be supported to join and leave the project consortium by providing them with all relevant project information. Consequently, there is a need for an overall model representing the different design, construction and management activities as well as the building objects, organisational and IT infrastructure of the project. The paper presents an approach towards a common meta-model for collaborative construction process management. Relevant construction project constraints will be identified and classified in order to develop a Construction Network Meta-Model. Furthermore, a Framework for the instantiation of Construction Networks will be introduced.
\end{abstract}

\section{INTRODUCTION}

Projects in the $\mathrm{AEC} / \mathrm{FM}^{1}$ area are characterized by a variety of technical and structural boundary conditions. Furthermore, heterogeneous organisational structures and various IT-Systems influence the realisation of a construction project. Particularly, the organisational structure is of great dynamic, since a project lifecycle passes several phases, for example 'planning phase', 'construction phase', or 'operational phase'. Each phase is conducted by its own organisational structure involving international companies as well as SME's. The need to rapidly establish new organisational structures and effectively manage this virtual organisation places high demands on the methods and models that are used for the specification of the project structure.

Large construction projects comprise thousands of individual building objects and activities, which are usually stored and managed in different information systems. Thus, to efficiently support construction project management and process coordination the project constraints should be described in a common and formal model with regard to domain specific requirements. By means of this model new

${ }^{1}$ Architecture, Engineering, Construction / Facility Management 
project partners and their IT-systems should easily be integrated and adjusted to the project life-cycle and the relevant constraints.

The aim of the paper is to present an approach for the development of a metamodel for the management of collaborative construction processes. This Construction Network Meta-Model will support the construction project coordination and can be applied for the semantic interoperability between the project information and the specification of business processes. Therefore, domain specific project requirements and data models have been analysed and applied as references for the initialisation of a specific construction project. This comprises geometrical information and semantic descriptions of the construction objects as well as functional and organisational aspects.

The paper will start with the introduction of a framework that guide the instantiation of a Construction Network Meta-Model. By means of this framework a Construction Network Instance will be specified to describe the constraints and dependencies of a particular project.

\section{A FRAMEWORK FOR CONSTRUCTION NETWORK INSTANTIATION}

The specification of the relevant information for the coordination of a virtual organisation for a certain construction project is a demanding and complex task. Therefore, a framework that provides guidelines for this activity has been developed. Through this framework the definition of a Construction Network Instance will be supported by a methodology consisting of four major steps as indicated in Figure 1.

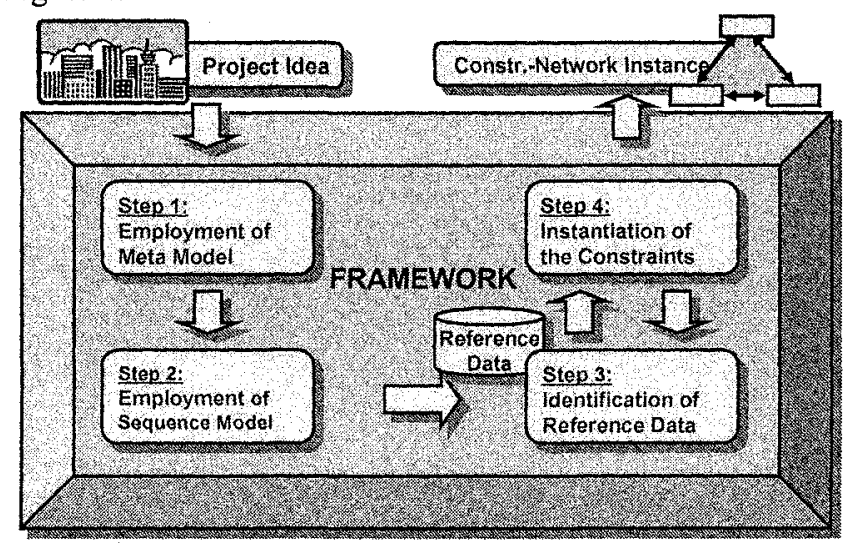

Figure 1 - Framework for initialisation of Construction Network Instances

Based on the project idea, a domain-specific meta model can be employed in step 1. This model identifies the elements, attributes and relations required for the description of the construction network. In step 2, a sequence model applicable for the employed meta model will be selected. The sequence model defines rules and constraints for the initialisation of the elements, attributes and their dependencies. In step 3, potential reference data for the meta model will be identified. For example 
the framework is providing different types of construction shapes, building functions or lifecycle phases. In step 4 , the reference data will be applied and/or modified to specify the boundary conditions of the particular project.

\section{CONSTRUCTION NETWORK CONSTRAINS}

Construction projects are defined as complex one of a kind projects. Thus, to derive a common meta model for collaborative construction project management for the proposed framework, its complexity has to be reduced by subdividing it into integral / coherent sub-projects or project views. Therefore, the entire project has to be decomposed into its controlling elements and structured in a reasonable manner. Based on various sources, interviews and project analyses, three dimensions that control the project performances have been identified, namely Project Organisation, Project Structure and Project Information. Each of these dimensions can be subdivided again into two and three categories, respectively. The dimensions and the belonging categories are depicted in Figure 2.

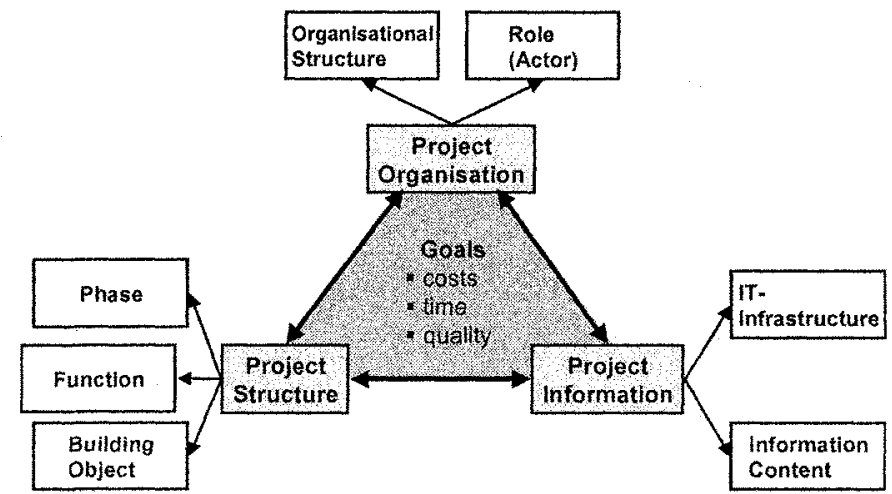

Figure 2 - Dependencies of the Construction Network constraints

Subsequent to the identification of the dimensions and categories, which influence the project development and construction management, typical models and data for these categories have to be identified and classified. Thus, several common building data standards and technical regulations were evaluated for its applicability to describe construction projects' constraints.

The following chapter gives an overview of the content and the requirements for the dimensions specifying a construction network. For each of these dimensions a partial model has been developed.

\subsection{Content and Models of the Construction Network}

\section{Project Organisation}

The project organisation determines the interrelationship between the participants and their roles/responsibilities in a project. It is usually set up by the project manager or the building owner in the beginning of the project, while considering legal and organisational aspects as well as best practise experiences. 
The requirements for the project organisation within construction projects are considerable, since several independent phases are passed through. Each phase has its own organisational structure with different partners and roles. Thus, the project organisation has to be adapted for each phase. The predefinition of the organisational arrangement within the project phases mainly depends on the building owner. In practice distinct organisational structures are realised, such as:

- Conventional / classical organisation

- Bidding consortium and joint venture

- General planner

- General contractor

Five key roles /actors in a construction project have been identified:

- Building owner

- Project manager

- Planner / Architect

- Construction companies / supplier

- Facility Manager

Each role has dedicated rights and duties in the different phases of the project and might be subdivided into several sub roles like 'interior architect' or 'landscape architect'.

\section{Project Structure}

The structure of a construction project is classified by three categories: 1) phases, 2) functions and 3) building objects. In practise combinations of these three categories are common, since a single structure leads to misunderstandings and will not cover the complexity of a construction project.

Different national as well as international regulations and recommendations specify the phases of the building life-cycle. For example, in Germany the HOAI ${ }^{2}$ standardizes the tasks and responsibilities of architects and engineers in construction projects. The HOAI is life-cycle oriented and catalogues the activities that have to be performed by architects and engineers in cooperation with other participants of the project. The required input and output documents, like technical drawings, are specified in the HOAI for each phase.

The focus of the function orientated project structure is on the performance of activities. This means that the overall project will be divided into its different activity-types. Each activity is performed by an actor of the project organisation and is linked to a building object. Within construction projects functions can be divided into primary functions and supporting functions. A sound example to structure a project by primary functions like 'masonry work' is provided by the German STLB ${ }^{3}$.

Building objects are components of one build artefact. By means of the building objects the entire building can be decomposed into its elements. This structuring can have two different foci:

\footnotetext{
${ }^{2}$ HOAI - 'Official Scale of Fees for Services by Architects and Engineers'. The HOAl structures the construction design and realisation process into nine phases.

${ }^{3}$ STLB: The "Standardleistungsbuch" (Standard Construction Service Manual) is a general, standardised, and hierarchical catalogue of text modules specifying of construction activities.
} 
- $\quad$ spatial focus (e.g. house $\rightarrow>$ floor $\rightarrow>$ room)

- element focus (e.g. wall, door or heating)

In consequence, to identify a certain construction item, it has to be localised in both foci; for example the 'window' in 'house IV, $2^{\text {nd }}$ floor, room 201 '.

Building Product Models (e.g. the IFC-2x model from the $\mathrm{IAI}^{4}$ ) provide a specification for the object oriented structuring of buildings. In addition, regulations like DIN $276^{5}$ 'building costs' and DIN $277^{6}$ 'areas and volumes of buildings' provide content for the building objects.

\section{Project Information}

The execution of larger building projects is nowadays hardly feasible without appropriate IT support. The information technology provides the means to carry out information exchange and data processing within and between the participating partners. In particular two scopes of information exchange among enterprises are of great importance for the inter-organizational management of building projects: 1) the IT-infrastructure systems and 2) the information content and structure.

The IT-infrastructure can be separated into IT systems for local information management such as building design software or calculation software and into IT systems for global information management such as document management server or 'building portals', accessible by several users. While the local systems are slightly influencing the construction processes the specification of the global systems are very important for the inter-organisational cooperation. Thus, addresses and interfaces of these systems have to be communicated to all partners.

For a sustainable exchange of project information it has to be structured in a coherent manner. Information standards serve for structured information exchange between application systems and should be specified by the partners in the beginning of the project. Katranuschkov et al. have identified several construction specific information standards for different construction activities [1].

\section{CONSTRUCTION NETWORK META-MODEL}

For a comprehensive specification of the constraints of construction projects the partial models for the identified categories of the construction network have to be integrated into an overall model, the Construction Network Meta-Model. By means of this model the required information for the collaborative project management is instantiated for a particular project and thus semantic interoperability between the dimensions is realized.

The general structure of the developed meta-model is depicted in Figure 3. In this model interrelationship between the categories of chapter 3 has been established according to the requirements that have been identified in the analysis of construction projects. The categories are represented by UML package diagrams to indicate that a more complex class diagram stands behind each package.

\footnotetext{
4 'International Alliance for Interoperability' within the construction and facilities management industries

${ }^{5}$ DIN 267 is used for the determination and classification of costs in building construction. It provides a structured list of building elements.

${ }^{6}$ DIN 277 provides a structured list for the occupancy of building spaces.
} 


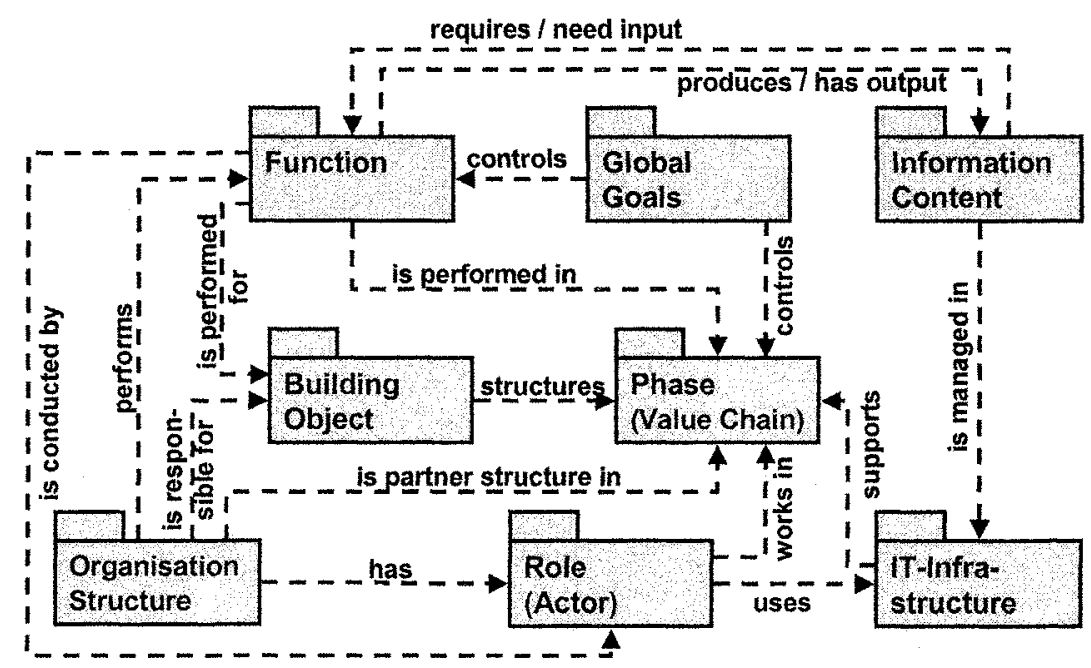

Figure 3 - UML package diagram of the Construction Network Meta-Model

The developed Construction Network Meta-Model will be capable to represent the following requirements for the inter-organisational collaboration of construction projects:

- The definition of the building life-cycle (phases) is the basis for the development of a construction project. Thus, the starting point for the construction network will be realised by the definition of the anticipated project phases on a high level (value chain).

- Building objects provide the spatial and element structure of a construction. However, each phase can have its individual focus on the object structure.

- Functions are the activities that have to be performed within each phase. A sequence of functions creates certain building objects. One function can contribute to the creation of multiple objects.

- Global goals will be defined to control the performance of the functions within the different phases. Thus, a comparison of the nominal with the actual goals is feasible.

- A specific role is responsible for the conduction of several functions within a certain phase of the project.

- The category organisational structure specifies the type of the co-operation and the project partners. The partners of the organisational structure are linked with one or more phases. Furthermore, one or more partners of the organisational structure can implement different functions, are responsible for several building objects and have one or more roles.

- Information content describes the required input and produced output information for each function.

- IT-infrastructure specifies the global services and systems that support the different phases of a project. Each role can have access to the ITinfrastructure with dedicated rights. The information content will be managed by the IT-infrastructure. 


\subsection{Sequence Model for the instantiation of a Construction Network}

According to the proposed framework in chapter 2 the instantiation of a Construction Network Instance for a specific project can be enhanced by the employment of a sequence model. Such a model supports the project partners to specify the content and its relations for the different categories of the meta model in a structured manner. For construction projects the sequence model should support iterations (loops), concurrency (AND-junctions) and decisions (OR-junction). Figure 4 displays a section of a feasible sequence model for the developed meta model on high level. This model is based on the UML-sequence diagram notation.

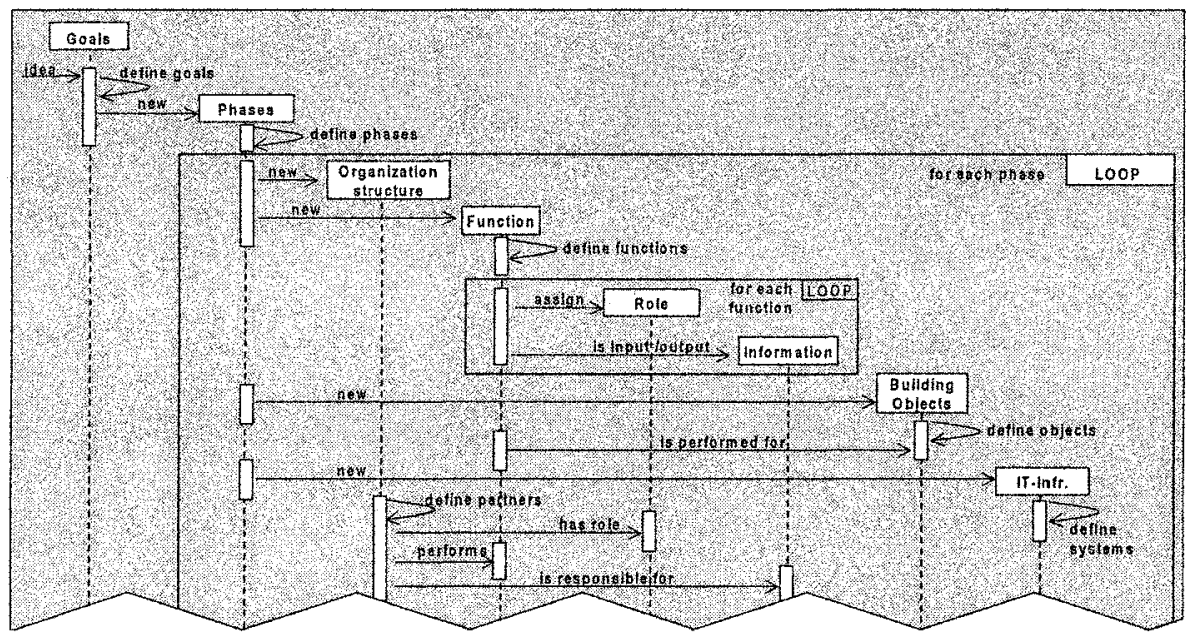

Figure 4 - Sequence model for Construction Network instantiation (example)

By means of the sequence model example in Figure 4 the instantiation of a Construction Network might be executed as follows (on a high level): After the definition of the project idea the global project goals will be specified. Next, the project will be divided into its mayor phases. For each phase the organisation structure and the functions including its belonging roles and the input/output information are defined. Following the definition of the building objects for a phase they can be linked to a specific function. Then, the different systems of the ITinfrastructure are identified.

\subsection{Applicability of the Construction Network Meta Model}

Once a Construction Network Instance has been instantiated, it can be applied to support the VO management of a construction project in several ways, e.g. by using predefined processes. Therefore, the Construction Network Instance provides the required context parameters for the selection and instantiation of the appropriate process module. Process modules are generally defined for the execution of a construction activity and can be adapted for constraints of a certain project. Flexible process-interfaces provide a seamless integration of instantiated processes modules into the existing workflow. An approach for the definition and use of process patterns for construction activities is described in Keller et al. 2004 [2]. 


\section{VERIFICATION AND CONCLUSION}

The management of projects in the building industry is influenced by several constraints. For example, the organisational structure of the projects is very heterogeneous. Partners and roles alter within the different phases of the building lifecycle. The need to rapidly establish new project structures and effectively manage these virtual organisations places high demands on the methods and models that are used for instantiation the project. Consequently, there is a need for an overall Construction Network Meta Model representing the different design, construction and management activities as well as the building objects, organisational and IT structure of the project.

The paper has demonstrated, that basically three dimensions, namely Project Organisation, Project Structure and Project Information, influence the performance of construction projects. Each dimension can be divided into categories that describe construction specific information like roles, functions, or data standards. Based on these results a Construction Network Meta Model has been developed. This meta model provides a schema for the definition of construction project constraints and can be integrated into a framework supporting the instantiation of a construction network. Several sources of reference data and models for the categories have been identified and can be used for the instantiation of a specific project in combination with a sequence model.

For the verification of the developed Construction Network Meta Model several projects with varying constraints about partner structure, functions, building components and IT-infrastructure have been analysed and evaluated. In particular the 'fault management process' has been investigated and decomposed into its categories and processes patterns.

\subsection{Acknowledgment}

This work has been conducted within the scope of the project 'Architecture for Collaborative Systems' (ArKoS) funded by the German Ministry for Education \& Research. Within the project an holistic architecture for the management of interenterprise cooperation in construction projects is developed by the project consortium [5].

\section{REFERENCES}

1. Katranuschkov P. Gehre A. Scherer R.J. Wix J. Liebich T. „User Requirements Capture in Distributed Project Environments:A Process-centred Approach". In Xth International Conference on Computing in Civil and Building Engineering, Weimar, 2004.

2. Keller M, Katranuschkov P, Menzel K. "Modelling collaborative processes for Virtual Organisations in the building industry" In proceedings of ECPPM, Balkema, 2004.

3. Keller M; Menzel K, Scherer R.J. "Use of Workflow-Patterns for Process Modelling in the Building Industry". In proceedings of PRO-VE, Lugano Switzerland, 2003

4. UML - Unified Modelling Language "UML 2.0 - Superstructure Specification" www.uml.org, 2004

5. Zang S, Adam O, Hofer A. Hammer C. Jerrentrup M. Leinenbach S. "Architecture for collaborative business process management - enabling dynamic collaboration" In proceedings of ECPPM, Balkema, 2004 